Portland State University

PDXScholar

12-10-1974

\title{
A Comparison and Item Analysis of Responses between Black Children and Language Delayed White Children on the Peabody Picture Vocabulary Test
}

Kevin N. Cole

Portland State University

Follow this and additional works at: https://pdxscholar.library.pdx.edu/open_access_etds

Part of the Speech Pathology and Audiology Commons Let us know how access to this document benefits you.

\section{Recommended Citation}

Cole, Kevin N., "A Comparison and Item Analysis of Responses between Black Children and Language Delayed White Children on the Peabody Picture Vocabulary Test" (1974). Dissertations and Theses. Paper 2129.

https://doi.org/10.15760/etd.2127

This Thesis is brought to you for free and open access. It has been accepted for inclusion in Dissertations and Theses by an authorized administrator of PDXScholar. Please contact us if we can make this document more accessible: pdxscholar@pdx.edu. 
AN ABSTRACT OF THE THESIS OF Kevin N. Cole for the Master of Science in Speech Pathology and Audiology presented Deoember 10, 1374.

Title: A Comparison and Item Analysis of Responses Between Black. Children and Language Delayed Thite Children on the Peabody Picture Vocabulary Test.

APPROVED BY MEMBERS OF THE THESIS COMMITTEE:

Joan McMahon, Chairman

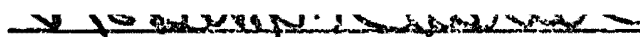

Robett L. Casteel

Robert H. English

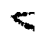

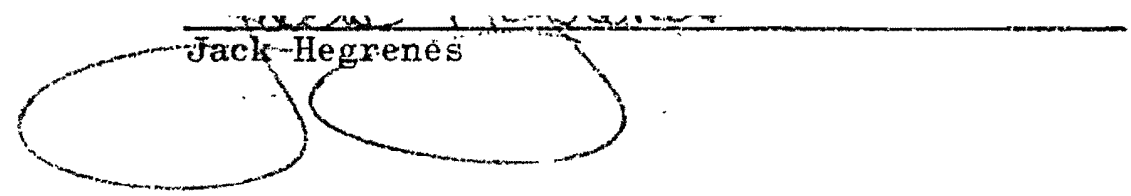

The purpose of this study was to compare PPVT scores of Black children and language delayed White children in order to determine whether the patterning of errors can be differentiated between the two groups. The study involved twenty BIack children and twenty language delayed White children between the ages of six years, six months, and seven years, six months. The sabjects were from families 
of lower socioeconomic status. The White subjects were given the Utah Test of Language Development to establish degree of language delay. The study was designed to determine whether either the language delayed White subjects or the Black subjects would miss any items on the PPVT significantly more often than the other group. The study sought to determine whether eithex group consistently made the same incorrect choice on items which they miss more frequently than the other group. Finally, the study was conducted to find whether the mean ceiling itern reached by the two groups would be significantly different.

The results of the study indicate the patterning of errors cannot be differentiated between the two groups. No significant difference was present between the mean ceiling item reached by the groups, and only two test items were missed significantly more often by the language delayed White subjects than by the Black subjects.

It is postulated that factors which might influence PFVT results in the Black population, as well as the White population, are: 1) the mean level of education of the community; 2) the residential stability of the population; and 3) the regional area from which new residents migrate. 
A COMPARISON AND ITEM ANALYSIS OF RESPONSES BETWEEN BLACK CHILDREN AND LANGUAGE DELAYED WHITE CHILDREN ON THE PEABODY PICTURE VOCABULARY TEST

\author{
by \\ KEVIN N. COLE
}

A thesis submitted in partial fulfillment of the requirements for the degree of

MASTER OF SCIENCE IN SPEECH:

EMPHASIS SPEECH PATHOLOGY AND AUDIOLOGY

Portland State University

1.974 
TO THE OFFICE OF GRADUATE STUDIES AND RESEARCH:

The members of the Committee approve the thesis of Kevin N. Cole presented December 10, 1974.

Joan McMahon, Chairman

Robert L. Casteel -

Robert H. English

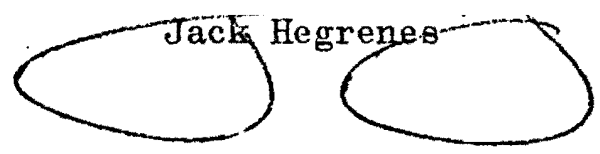

APPROVED:

Rdbert W. Jagelsahg. Head./Wepartment of Speech Communication

David T. Clark, Dean of Graduate Studies and Research

December 10, 1974 


\section{ACKNOWLEDGMENTS}

I wish to thank Joan McMahon, Chairman, for her suggestions, directions, encouragement, flashes of unparalleled brilliance, and worry. Without her support this thesis would not have been possible. Special appreciation is felt for Margaret Callahan and Vicki Wood, who offered their time and efforts so unselfishly to aid me in the collection of data for the study. I also wish to thank Joe Hopkins, Marilyn Neher, and Bev Dixon, who provided the understanding and assistance which made it possible for me to continue work on this study during my student practicum.

Much gratitude is owed also to Jack Hegrenes, whose concern for people (and statistics), combined with unbounded patience, allowed me to have a better understanding of the results of this thesis.

Finally, I wish to thank Dr. Casteel and Dr. English for their aid in this study, as well as their contributions to my personal and professional growth. It is great fortune to be influenced by sincere individuals. 
TABLE OF CONTENTS

PAGE

ACKNOWLEDGMENTS . . . . . . . . . . . . . . •

LIST OF TABLES. . . . . . . . . . . . . . .

CHAPTER

I INTRODUCTION. . . . . . . . . . . . 1

II REVIEW OF THE LITERATURE. . . . . . . . . . 3

Verbal Destitution. . . . . . . . 3

Underdeveloped Language System. . . . . . 5

Non-standard Language . . . . . . . . 6

III METHODS AND PROCEDURES. . . . . . . . . . 13

Screening . . . . . . . . . . . 13

Evaluation. ............. 14

Scoring . . . . . . . . . . . 15

Data Analysis . . . . . . . . . 16

IV RESULTS AND DISCUSSION. . . . . . . . . 17

Results . . . . . . . . . . 17

Discussion. . . . . . . . . . 25

V SUMMARY AND IMPLICATIONS. . . . . . . . . 32

Summary . . . . . . . . . . . 32

Implications for Clinic and Future Research . 33

REFERFNCES. . . . . . . . . . . . . . . . 


\section{LIST OF TABLES}

TABLE

PAGE

I Summary of Statistics for the PPVT Showing the Variables of Age, Ceiling Item, Raw Score, and Language Delay . . . .

II Distribution of Answers for Items 39 and $56 . .$.

III Percentage of Items Missed on the PPVT by Black and White Subjects in the Kresheck and Nicolosi Study, and in the Present Study. .

IV Summary of Statistics of the PPVT for Male and Female Subjects Showing the Variables of Mean Age, Mean Ceiling Item, Mean Raw Score, Mean M.A., and Mean Language Delay . . . . . . . . . . . . . . . 


\section{CHAPTER I}

\section{INTRODUCTION}

Diagnosis and treatment of language disorders among $\mathrm{Black}$ children is becoming of increasing concern to the Speech Clinician, and this involves a number of special considerations. Wolfram (1972) and Baratz (1969), among others, suggest one consideration in the diagnosis of language disorders among Black children involves distinguishing between authentic language disorders and cultural language differences.

If the Speech Clinician is to make this distinction, it follows that the instruments used for the assessment of language ability should be constructed in such a way as to differentiate between language patterns which reflect a non-standard cultural background, and language which is deficient in content and structure due to pathological conditions. If the instrument does not clarify this distinction it is possible that Black children will be diagnosed as deficient in language when, in fact, the children have a culturally different background rather than a language deficit.

The instrument most frequently used for assessment of language comprehension, according to a study done by the Committee on Language, American Speech and Hearing Association (Stark, 1971), is the Peabody Picture Vocabulary Test (PPVT). In using this test as a means of assessing the language ability of Black children, it may be meaningful to the Speech Clinician to know whether the results are indicative of 
a language deficiency requiring clinical intervention, or merely a reflection of a non-standard language background.

\section{STATEMENT OF THE PROBLEM}

The purpose of the present study was to compare Peabody Picture Vocabulary Test results between Black children and language delayed White children in order to determine whether the patterning of error responses could be differentiated between the two groups. Answers to three questions were sought:

1. Are there items which are missed significantly more often by one group than by the other?

2. Does either group consistently make the same incorrect choice on items which they miss significantly more often than the other group?

3. Will either group achieve a mean ceiling item score significantly higher than the other? 


\section{CHAPTER II}

\section{REVIEW OF THE LITERATURE}

A number of authors (Dillard, 1966; Frazier, 1964; Bonner and Beleden, 1970) have attempted to determine whether a legitimate distinction can be made between language which is culturally different from the norm, and language which is substandard or disordered. This distinction appears to involve all parameters of language including vocabulary skills (Robinson and Mukerji, 1965; Baratz, 1969).

According to Frazier (1964), the viewpoints concerning language patterns that vary from standard English can be categorized into three main types: 1) those attributing the language patterns to true verbal destitution; 2) those attributing them to an underdeveloped language system; and 3) those contending the language patterns reflect the use of a full but non-standard language system.

\section{VERBAL DESTITUTION}

According to the first viewpoint, language patterns which vary from standard English are thought to deviate due to a lack of experience and stimulation on the part of the speaker. Robinson and Mukerji (1965) appear to support this theory, and state there is little possibility for real progress in understanding ". . unless these children can enlarge their vocabularies through personally gleaned informatior." 
These authors consider the lack of a functional vocabulary to be the main deficit resulting from the experiential deprivation.

Raph (1965) outlines specific environmental factors that are said to be involved in the language problems of socially disadvantaged children. These factors include lack of vocal stimulation during infancy, lack of conversation with adults, and lack of opportunity to develop mature cognitive behavior. The verbal expression of the socially disadvantaged child is described by Raph as containing a meagerness of quality and quantity, as well as a slower rate of speech and a lower level of articulatory maturation.

A study by Deutsch (1965) also related language patterns of lower socioeconomic and Black children to experiential deficiencies resulting from environmental conditions. The study involved a core sample of 292 children in the first and fifth grades, and an extended sample of 2,500 children. The subjects were of different socioeconomic backgrounds, as well as different ethnic backgrounds. Deutsch attempted to relate these background variables to specific cognitive and linguistic patterns, and it was concluded that the low socioeconomic status and Black subjects performed below the norm on the battery of language tests that were administered. The author suggested these individuals need remedial and enrichment programs that follow developm mental stages in order to arrest the cumulative language deficit before it increases (Deutsch, 1965).

When comparing the linguistic abilities of children from various backgrounds it was found by Deutsch that a lower socioeconomic background, whether the child was Black or White, resulted in scores lower 
than the norm on a number of language tests, including the PPVT. In addition, Blacks, regardless of economic class, scored lower than the norm in language ability. Subjects who were both Black and from a lower socioeconomic background, however, did not earn disproportionately lower language scores. This finding might indicate that information concerning the language ability of Blacks, or individuals from a lower socioeconomic background, might be applicable to both.

\section{UNDERDEVELOPED LANGUAGE SYSTEM}

A second approach to non-standard language views it as resulting from an underdeveloped language system. According to Baratz (1968), this viewpoint holds that the language system of the child does not allow language to function in aiding cognitive development. Attributing non-standard language to an underdeveloped language system differs from the "verbal destitution" theory in that the child is thought to have an adequate repertoire of experiences, but is unable to organize these experiences linguistically due to a deficient language system.

Authors who attribute the non-standard language of culturally deprived and Black children to an underdeveloped language system include Bereiter and Englemann (1966), and John (1963). Bereiter and Englemann contend that the language used by individuals from a lower socioeconomic background is primarily concerned with the expression of emotions, controlling behavior, and other social functions. Nonstandard language is said, by the authors, to lack a means of describing, inquiring, instructing, hypothesizing, comparing, analyzing, 
deducing, and testing. Bereiter and Englemann also state that "Lowerclass and middle-class children speak essentially the same language, but lower-class children are about a year behind in their mastery." This full year of language delay is considered, by the authors, to involve vocabulary skills as well as other parameters of language. John (1963), in a study of the relationship between early social environment and the patterning of intellectual skills, found that middle-class Blacks had larger vocabulary skills than lower-class children who were Black. The study involved 250 Black children in the first and fifth grades who were of varied socioeconomic status. Skills such as labeling and categorizing were measured, and it was found that lower socioeconomic Black childrea could label test items, but could not arrange them into categories. John concluded from this that lower socioeconomic Black children did not use language to form abstractions as did middle-class Black children. Several factors were identified by the author which were said to influence the language of lower-class Blacks. These include the lack of opportunity to categorize, and a lack of language feedback. It is interesting to note that John used the PPVT as one measure of language ability. Mean scores of 57.5 , 55.3, and 62.8 were cited for lower-lower, upper-lower, and middleclass groups of Black first graders, respectively.

\section{NON-STANDARD LANGUAGE}

A third manner of viewing language that is different from the norm, according to Frazier $(1964)$, is to consider it to be fully developed but non-standard language. Frazier states that some children 
may have full language development, but not of the kind most valued in the school environment. Because of a lack of conceptualization of experience in areas expected of school beginners, Frazier postulates that some children appear to be suffering from language underdevelopment, when in fact they are not. Several other authors, including Baratz (1968; 1969), Dillard (1966), Wolfram (1972), and Hopper and Naremore (1973), consider this viewpoint to be the most accurate in describing Black language.

Baratz (1968) states that studies which suggest children from lower socioeconomic backgrounds exhibit verbal destitution can be explained in terms of experimental procedures. She contends the material used to elicit the data, the experimental setting, and interaction with the experimenter are situations and events which are more familiar to the middle-class child than to the lower-class child.

Baratz (1969), in a critique of studies which suggest the culturally disadvantaged child has less language than the middle-class child, noted that most studies used standard English as the criteria for normal and adequate language. In her refutation of the use of White norms for Blacks she quotes Bernard (1965), who states:

The use of White control groups to describe who the Negro is actually results in "studies of the White population with emphasis on Negro or non-White data as representing deviance from a white norm." This unhappy state of affairs has led the social sciences to create a picture of the Negro as a "sick White man."

Wolfram (1972) also contends that using norms established on one ethnic group to judge others is not a legitimate practice. He states that linguistic systems are arbitrary, and are established only by convention. This contention is supported by many linguists, including 
Nida (1964) and Pierce (1973). It is thought by Wolfram to be inappropriate to judge one arbitrary linguistic system in relation to another.

Wolfram also hypothesizes "All languages are equally capable of conceptualization and expressing logical propositions, but the mode for conceptualization may differ drastically between two systems." This idea that Black language involves a complete but different language system also is supported by Dillard $(1966 ; 1972)$. It is postulated by Dillard that Black language is different from standard English, in part, due to the use of grammatical structures of African languages. This is in opposition to the belief that the difference is caused merely by a misuse of standard English.

Although differences in structure are said to exist, Labov (1970) states that the few differences in syntax occur mostly in surface structures, and that differences in deep structures seem small. This supports the belief held by Baratz (1968) that:

The economically disadvantaged child does have a language; he has learned to speak. What he has not learned is how to speak standard English--not because he is physically or genetically different or because he comes from a broken home where his parents are frequently absent, but because he has not been in a language environment where standard English is spoken.

Hopper and Naremore (1973) have labeled this approach to nonstandard Fnglish a "difference theory," suggesting educational problems are not caused by the child's lack of language, but because the school system offers only alien language. This view can be contrasted with both the "verbal destitution" and "underdeveloped language" theories, which represent Black language as a disorganized version of standard 
English. Hopper and Naremore label this type of approach to nonstandard language the "deficit theory."

According to Baratz (1969) and Dillard (1966), one fundamental difference between the deficit theory and the difference theory is that the first assumes one language system is better than another. According to Baratz, however, it is only better during some times and in some places. Dillard states that the lower socioeconomic Black is typically told that he must give up "bad grammar," whereas a linguistically oriented statement would be that he should acquire a second grammatical system in addition to the first, with no weighting of value in favor of one or the other. Baratz (1968) further argues that with the difference theory one does not destroy, eliminate, or replace existing language patterns. Rather, one teaches standard English as a second language so the child can function linquistically witbin both cultures.

Since the Peabody Picture Vocabulary Test is sometimes used to determine the educational disposition of Black children, as well as White children (Bonner and Beleden, 1970), it is helpful to examine information that has been gathered concerning the use of this test with Blacks.

According to Dunn (1965), the author of the PPVT, the test was standardized using 4,012 White children from the Nashville, Tennessee, area, ranging in age from two years, six inonths, to eighteen years. This fact has led Lyman (1965) to conclude that "Considerable caution needs to be used in interpreting the norms, especially in communities other than Nashville." 
Several studies have been conducted comparing the PPVT with other language and I.Q. tests using Black subjects, in order to examine the validity of the PPVT with this ethnic group. Milgram and 0zer (1967) compared Stanford-Binet scores and PPVT scores of fifty-one Black subjects. It was found that the mean PPVT score of three-yearolds was four months below the mean ascribed by the Stanford-Binet. At the four-year-level the PPVT scores averaged ten months below the Stanford-Binet, and at the five-year-level, a full year below the Stanford-Binet. It was not postulated why the PPVT gave a decreasing estimate of Black children's language ability in relation to the Stanford-Binet as age increased. Perhaps a cultural language difference influences PPVT results more than Stanford-Binet results because the PPVT measures only receptive vocabulary rather than a broad area of intellectual skills.

Another study involving inter-test comparisons of the scores of Black youths was conducted by Bonner and Beleden (1970). These authors compared PPVT scores and Wechsler Adult Intelligence Scale (WAIS) scores of sixty subjects between the ages of sixteen years and eighteen years, five months. The authors concluded from the study that there was a positive significant correlation between the two tests, although the PPVT I.Q. scores were somewhat lower than the WAIS scores. The results of the study showed that although the PPVT $I, Q$. scores have a high correlation with the WAIS Full Scale I.Q., the agreement between the Verbal I.Q. of the WAIS and the PPVT I.Q. correlated the least of the three I.Q. scores derived from the WAIS. 
Baratz (1969) has suggested that the vocabulary items on the PPVT may be used differently by Black children, which might lead the tester to feel the child is lacking in a particular concept. She cites the item "building," which the PPVT asks the child to identify. The correct response on the PPVT is the picture of men constructing an edifice. In Negro non-standard vernacular, according to Baratz, "building" is used only as a noun. In Negro non-standard English one "makes an edifice." This difference in vocabulary could perhaps lead the tester to feel the child is lacking in a concept, rather than simply using a different language system.

Mandel (1970) also has concluded that specific items of the PPVT may be culturally biased. He states that special weights should be developed for particular test items, or that separate norms be developed for users of non-standard English.

Gilmore (1967) compared the PPVT scores of subjects according to race, place of residence, and socioeconomic status, and found a significant difference related to race and place of residence, but not socioeconomic status. Blacks scored lower than Whites, and rural subjects scored lower than urban subjects.

There is evidence indicating Black subjects tend to score below Whites on the PPVT, although there are few attempts to determine why this is occurring. A study by Kresheck and Nicolosi (1973) has attempted to examine this question by performing an item analysis of Black and White subject's scores. The study involved fifty Black and fifty White students from Title I funded schools who were of similar socioeconomic background (lower-middle class). They also were matched 
for age and grade level. The age range of subjects was from five years, six months, to six years, six months. The mean raw score was forty-eight for Black subjects and fifty-nine for White subjects. The Black subjects scored approximately one year, ten months below the White subjects on the PPVT I.Q. scale.

An error analysis was made which showed that "Some words on the PYVT were missed by a large percentage of the Black population, which was not the case for the White population." In addition, on some items which were missed Blacks consistently chose the same incorrect item to represent the word. An example cited by Kresheck and Nicolosi (1973) was the item "caboose" (plate 32). The item was missed by more than half of the Black children. Of those who missed the item, $80 \%$ chose "tank" to represent "caboose."

The authors concluded that "The PPVT appears to be a questionable test of Black children's receptive vocabulary." This study, as well as the studies by Mandel (1970) and Gilmore (1967), indicates that Black subjects do less well on the PPVT than do speakers of standard English. There appear, however, to be little data suggesting whether this depressed score is caused by a linguistic deficit, or by the use of a different linquistic system.

The present study was designed to investigate the possibility of differentiating between language which is deficient, and language which is merely non-standard. The study will operationally accept the "non-standard language" point of view, which contends that Black children tend to. score lower on the PPVT due to use of an adequate but culturally different language system. 


\section{CHAPTER III}

\section{METHODS AND PROCEDURES}

The present study involved twenty Black subjects and twenty language delayed White subjects ranging in age from six years, six months, to seven years, six months. Subjects were matched for grade level as well as socioeconomic status (SES). Black subjects were chosen from second grade classes in public schools in the Portland metropolitan area. Socioeconomic status was determined by the occupation of the head of household as outlined in Methodology and Scores of Socioeconomic Status: Working Paper No. 15 (U.S. Bureau of Census, 1960). In one school SES information was obtained by the principal due to confidentiality requirements.

\section{SCREENING}

Children with reported physical handicaps which may have interfered with communicative ability were excluded from the sampling. All subjects passed a hearing screening for the frequencies of 500 , 1,000, and 2,000 Hertz at $25 \mathrm{~dB}$. Hearing Level. The audiometeric screening was administered in the school building which subjects attended. The screening was conducted prior to the administration of the PPVT, and any subject who did not respond to the tested frequencies was excluded from the study. 
The Utah Test of Language Development (UTLD) was administered to all White subjects passing the audiological screening. Testing was done by this researcher according to the procedures described in the manual of instructions for the UTLD. A language-age-equivalent score from eighteen to thirty months below the subject's chronological age was required for the subject to participate in the study. This range of language delay was chosen for White subjects since it corresponds with the mean degree of language delay achieved by the Black subjects on the PPVT in the Kresheck and Nicolosi study.

\section{EVALUATION}

Once the children were located and had met the screening criteria, the PPVT (form A) was. administered by Margaret Callahan, Speech Pathologist. Testing was conducted within the schools the subjects attended. The test was administered according to the procedures described in the manual of instructions for the PPVT (Dunn, 1965), with one exception: All subjects began with test item number one. This was done to determine whether either group of subjects would miss any of the earlier test items more frequently than the other group.

In administering the PPVT, the examiner recorded the number of the cell which the subjects identified as representing the vocabulary word. In all cases, administration of the PPVT was conducted within one week of administration of the hearing and language screening. The entire testing was completed within a six-week period. 
Peabody Picture Vocabulary Test (PPVT)

The PPVT is an instrument designed to evaluate receptive vocabulary skills. In administering the test, the examiner presents verbally a single word vocabulary item to the subject, who responds by identifying one picture of four possible pictures as representing the vocabulary item. Results of the test are interpreted in terms of a Mental Age score, as well as an I.Q. score.

Utah Test of Language Development (UTID)

The UTLD was designed to evaluate a broad spectrum of language skills, including receptive vocabulary. The test contains items involving auditory sequential memory, visual-motor skills, reading and writing proficiency, and expressive and receptive semantic skills. The results of the UTLD are evaluated in terms of a "language-ageequivalent" score.

\section{SCORING}

All tests were scored by this researcher according to the procedures outlined in the manuals of instruction for the PPVT and UTLD. Since the PPVT was begun with item number one several subjects missed an item, then achieved a basal score by achieving eight consecutive correct responses. All incorrect responses, including those below the basal item, were subtracted from the ceiling item in order to obtain the raw score. 
DATA ANALYSIS

Chi square analysis was used to determine whether either group missed individual test items significantly more often than the other group. 
CHAPTER IV

RESULTS AND DISCUSSION

RESULTS

The purpose of the present study was to compare Peabody Picture Vocabulary Test results between Black children and language delayed White children in the greater Portland area in order to determine whether the patterning of error responses could be differentiated between the two groups. Answers to three questions were sought:

1. Are there items which are missed significantly more often by one group than by the other?

2. Does either group consistently make the same incorrect choice on items which they miss significantly more often than the othex group?

3. Will either group achieve a mean ceiling item score significantly higher than the other?

The Peabody Picture Vocabulary Test (PPVT) was administered to twenty Black children and twenty language delayed White children ranging in age from six years, six months, to seven years, six months. All subjects were second-grade students from schools in the Portland metropolitan area. Subjects were identified by school principals as being of lower socioeconomic status when it was not possible to obtain information as to the occupation of the head of the household. When this information was available socioeconomic status was determined by this factor according to the criteria of Methodology and Scores of 
Socioeconomic Status: Working Paper No. 15 (U.S. Bureau of Census, 1960).

Degree of language delay for White subjects was between eighteen and thirty months, as determined by the results of the Utah Test of Language Development (Mecham and others, 1969). The mean degree of delay on the UTLD was twenty-two months, with a standard deviation of 4.52 months.

\section{PPVT Results}

The results of the PPVT indicate that Black subjects and language delayed White subjects in the Portland metropolitan area achieve approximately the same raw score, with the Black subjects receiving a slightly higher raw score. Black subjects also achieved a slightly higher ceiling item, although this was not statistically significant at the .05 level.

The degree of language delay ascribed by the PPVT was calculated by subtracting the subject's chronological age from the PPVT mental age score. The Black subject's mean length of delay of 6.3 months was 1.1 month less than the 7.4 month delay received by the White subjects. This difference, however, was not significant at the .05 level.

The mental age ascribed by the PPVT for Black subjects was 4.1 months greater than that of the White subjects, with Black subjects receiving an M.A. mean score of 80.20 , as shown in Table $I$.

\section{Item Analysis}

Individual items of the PPVi were examined by the use of chi square analysis to determine if there were items which were missed more 
TABLE I

SUMMARY OF STATISTICS FOR THE PPVT SHOWING THE

VARIABLES OF AGE, CEILING ITEM,

RAW SCORE, AND IAANGUAGE DELAY

Black Subjects

\begin{tabular}{lrrrr}
\hline Variables & Low & High & Average & Std.Dev. \\
\hline Age (years) & 6.5 & 7.5 & 7.21 & 3.29 \\
Delay (months) & +26.0 & -18.0 & -6.3 & -10.75 \\
M.A. (months) & 67.0 & 116.0 & 80.20 & 11.24 \\
Raw Score & 53.0 & 74.0 & 59.05 & 4.78 \\
Ceiling Item & 62.0 & 88.0 & 68.25 & 6.11
\end{tabular}

Language Delayed White Subjects

\begin{tabular}{lcccc}
\hline Variables & Low & High & Average & Std.Dev. \\
\hline Age (years) & 6.58 & 7.5 & 7.0 & 3.80 \\
Delay (months) & +10.0 & -26.0 & -7.4 & -8.87 \\
M.A. (months) & 55.0 & 94.0 & 76.1 & 10.20 \\
Raw Score & 46.0 & 65.0 & 57.0 & 4.82 \\
Ceiling Item & 52.0 & 78.0 & 67.1 & 6.0
\end{tabular}

frequently by one group of subjects than bythe other. Table II shows those items which were answered incorrectly by the White subjects more often than by the Black subjects to a degree that was statistically significant at the .05 level. There were no j.tems which were answered incorrectly more often by the Black subjects than by the language delayed White subjects at that level of significance. 
TABLE II

DISTRIBUTION OF ANSWERS FOR ITEMS 39 AND 56

White Subjects

Black Subjects

Item 39 (coach)

$(\mathbf{P}<.01)$
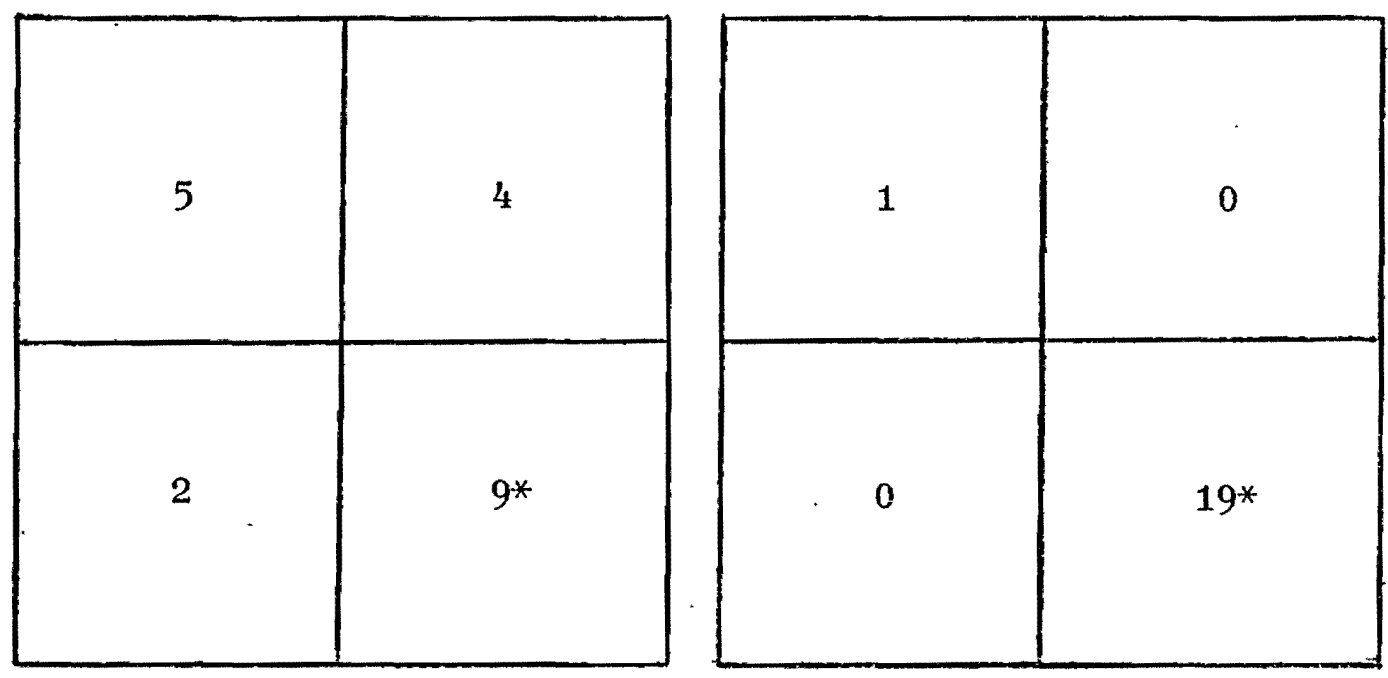

Item $56\left\{\begin{array}{l}\text { transportation }) \\ (\mathrm{P}<.01)\end{array}\right.$
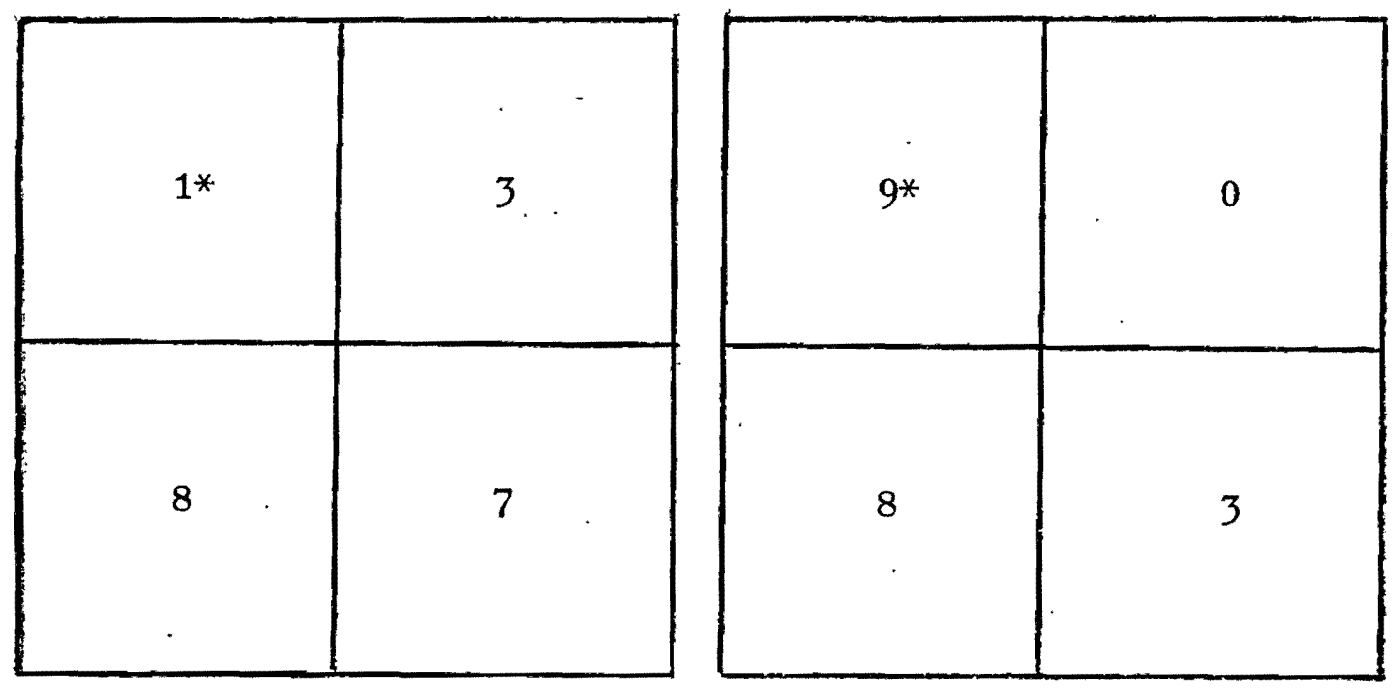

Asterisked cell is correct answer 
The items missed significantly more often by the White subjects were "coach" (item number 39) and "transportation" (item number 56). Table III shows the number of Black and White subjects who missed each item of the PPVT. The table also shows the distribution of errors from the Kresheck and Nicolosi study.

\section{Male and Female Differences}

A summary of male and female differences in PPVT results is shown in Table IV. For both Black and White subjects, female subjects received lower Mental Age scores and were delayed to a greater degree in language than the males. The degree of language delay was calculated by subtracting the subject's Mental Age score from the subject's chronological age. The mean delay in months for the White female subjects was 7.6 months greater than the mean delay for White male subjects. The mean delay for Black female subjects was 4.4 months greater than the mean delay for Black male subjects. 
TABLE III

PERCENTAGE OF ITEMS MISSED ON THE PPVT BY BLACK AND WHITE SUBJECTS IN THE KRESHECK AND NICOLOSI

STUDY, AND IN THE PRESENT STUDY

Item Number

11 -

12

13

14

15

16

17

18

19

20

21

22

23

24

25

26

27 -

28 -

29

30

31

$32=$

33

34 -

35
Item Number

11 -

12

13

14

- $-\cdots-$ = Black

15 --

16 -

17

$18=-$

19

20

21 --

$22 \cdots$

$23-$

$24=-$

25

26 -

27 -..-

28 ---

29

$30-$

$31=$

$32=$

33 -

$34=$

$35=$ = White $\begin{array}{lllll}0 \% & 25 & 50 & 75 & 100\end{array}$

Present Study 
TABLE III (continued)

Item Number

$36=$

37 -

38

$39=$

$40=$

41

42 --

43

44

45

$46=$

47

48

$49=$

$50=$

$51=$

$52=-\cdots$

$53-$

$54=$

$55=$

56 그.-‥-

$57=$

58 -ㅡ-

59 ב-בי-

60 =-‥-‥-

61 그

62 =----

63 =- -

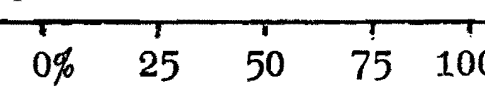

Present Study
Item Number

$36=-\cdots$

$37=-$

38 -

$39=$

$40=$

$41--$

$42=-\cdots$

$43-\cdots$

$44=$

$45=-$

46 -----

$47=$

$48=$

$49=-$

$50=-$

$51=-\cdots$

$52=$

$53=$

54 =-1-

$55=-$

56 그.-…-

57 =--

58 =--

59 프--

60 프-

61 =----

62 프

$63=--$

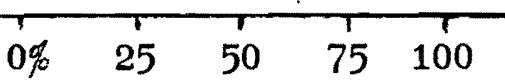

Kresheck \& Nicolosi Study 
TABLE III (continued)

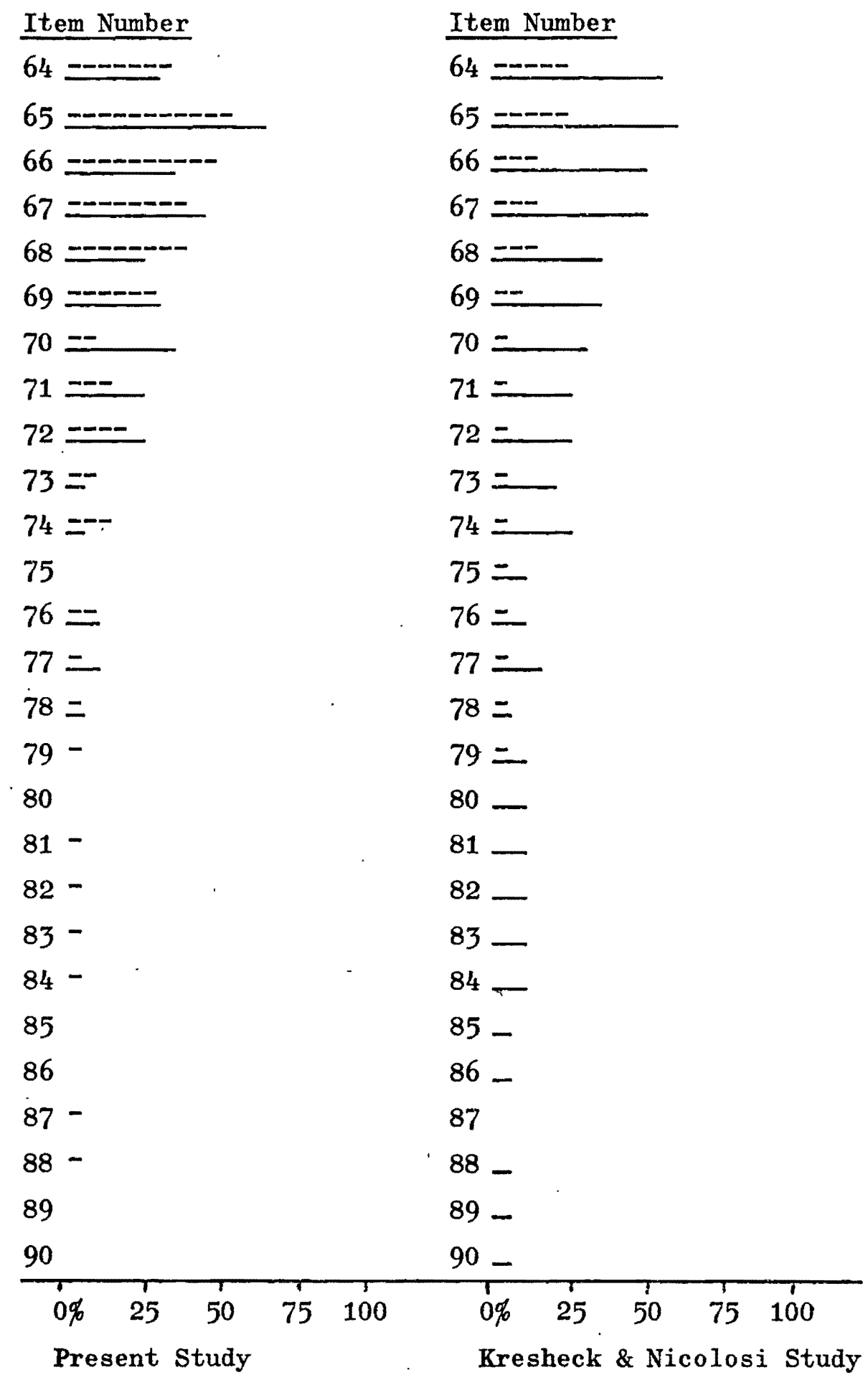


TABLE IV

SUMMARY OF STATISTICS OF' THE PPVT FOR MALE AND FEMAIE SUBJECTS SHOWING THE VARLABLES OF MEAN AGE, MEAN CEILING ITEM, MEAN RAW SCORE, MEAN M.A., AND MEAN LANGUAGE DELAY

\begin{tabular}{lrrrr}
\hline Variables & $\begin{array}{r}\text { Black } \\
\text { Female }\end{array}$ & $\begin{array}{r}\text { Black } \\
\text { Male }\end{array}$ & $\begin{array}{r}\text { White } \\
\text { Female }\end{array}$ & $\begin{array}{r}\text { White } \\
\text { Male }\end{array}$ \\
\hline Age (months) & 87.1 & 85.9 & 84.6 & 83.4 \\
Ceiling Item & 67.0 & 69.5 & 65.4 & 69.2 \\
Raw Score & 58.4 & 59.7 & 55.4 & 59.0 \\
M.A. (months) & 78.6 & 81.8 & 72.7 & 80.2 \\
Delay (months) & 8.5 & 4.1 & 10.8 & 3.2
\end{tabular}

\section{DISCUSSION}

The intention of this investigation was to determine whether there were differences in the patterning of errors between PPVT results of Black children and language delayed White children in the Portland metropolitan area. The major question asked was "Are there test items which are missed more frequently by one group than the other?" The results, as shown in Table III, indicate that no items which were presented to the subjects were missed significantly more often by the Black subjects than by the language delayed White subjects. Two items, however, were missed significantly more often by the language delayed White subjects than by the Black subjects. Item number 39 (coach) was missed by $50 \%$ of the language delayed white subjects, as compared with 5\% by the Black subjects. Item number 55 (transportation) was missed by $90 \%$ of the language delayed white subjects, as compared with $55 \%$ for the Black subjects. It should be noted that the .01 level of 
significance for only two items does not necessarily constitute a trend, since it would be expected that there would be some variation in significance among the seventy-seven test items examined.

These results contrast with those of the study by Kresheck and Nicolosi (1973) where it was found that Black subjects missed several test items more often than did a group of White subjects who were matched for age, grade level, and socioeconomic status. In the Kresheck and Nicolosi study Black subjects received a mean M.A. score approximately twenty-two months below that of the White subjects.

A conceivable explanation for the fact that Black subjects missed specific items frequently in the Kresheck and Nicolosi study, but not in the present study, would be that the Black population in the Portland metropolitan area has a higher educational level than the Black population of Rockford, Illinois, where the Kresheck and Nicolosi study was conducted. According to Census Tracts (U.S. Bureau of Census, 1972a; 1972b) for the areas. in and around Rockford, Illinois, and Portland, Oregon, the Black population in Portland has attained a higher level of education than the Black population of Rockford, Illinois. The mean number of years of school completed by Blacks over age twentyfive years in Portland was reported to be 11.1 . The mean number of years of school completed by Blacks over age twenty-five in Rockford was 9.9 .

The educational level of Portland metropolitan area Black subjects was reported to be approximately 1.3 years less than the mean educational level for the total population of the area. The educational level of the Rockford area Black population, however, was 
approximately three years below the mean educational level for the total population of that area (U.S. Bureau of Census, 1972b). The mean levels of education for the total populations of Portland, Oregon, and Rockford, Illinois, were 12.4 and 12.9 years, respectively. These factors might contribute to the difference in PPVT results of the two populations, since a community with a higher educational level may use a more standardized language system.

The second question asked in this study was "Does either group consistently make the same incorrect choice on items which they miss more frequently than the other group?" Table II shows the distribution of answers for the two items which were missed significantly more often by one group than by the other. Incorrect choices by the language de-layed White subjects are distributed among all three of the possible incorrect choices for both items. This pattern of distribution of errors suggests the words "coach" and "transportation" were not part of the language delayed White subject's receptive vocabulary. The pattern gives no indication that the words held a different meaning which led the subjects to choose an incorrect item rather than the correct item.

It was originally anticipated that Black subjects would miss certain items more frequently than language delayed White subjects, and that Black subjects would tend to choose the same incorrect item to represent the vocabulary word on items frequently missed, as in the Kresheck and Nicolosi study (1973). In the present study, however, Black subjects did not miss any items significantly more frequently than did language delayed white subjects. 
These results might be expiained in terms of a regional bias which is thought to be present in the PPVT (Jensen, 1973a). An example of this bias may be seen in items such as "bronco," which is a term used more often on the West coast than in other areas, and the item "dorimer," which is said to be a term better known to Eastern residents (Jensen, 1973b). Populations which are regionally different may tend to answer various items on the test differently.

Census data (U.S. Bureau of Census, 1972b) indicate that the Black population of Rockford, Illinois, with a "new resident" rate of approximately $17 \%$, is less regionally stable than the total population of that city, with $12 \%$ of its residents moving to the area from other regional areas. The Black population of Rockford also is less regionally stable than the Black population of Portland, Oregon, which has approximately $13 \%$ of its population entering the area from a different region of the country. The total population of Portland has a new resident rate of $17 \%$.

Of the Black population which moved to Rockford within five years of the census date, $60 \%$ were from the Southern United States, with the remaining $40 \%$ from all other areas. Only $39 \%$ of the Black population moving into the Portland metropolitan area were from the Southern United States.

The difference between the Kresheck and Nicolosi results, and the results of the present study, may be related to the fact that the Black population of Rockford is composed of a greater percentage of new residents arriving from other regional areas, and that the influx of Black residents is primarily from one regional area of the country. This 
might produce a situation where Black subjects would tend to identify certain PPVT items incorrectly, according to a regionally different word usage common to individuals who previously lived in the same area.

Since the Black population in the Portland metropolitan area is reportedly more stable, residentially, than the total population of the Portland metropolitan area, and since a smaller percentage of the new residents are from a single regional area, une could expect a regional bias in the PPVT to have little influence on test results of the Black population in the Portland metropolitan area.

A third question asked in this study was "Will one group reach a significantly higher mean ceiling item than the other group?" The Black subjects reached a higher ceiling item than did the language delayed White subjects, as well as a higher raw score. It was anticipated that the Black subjects would reach a higher mean ceiling item, but would have a mean raw score similar to that of the language delayed White subjects due to errors on certain items which would not be missed by the language delayed White subjects.

A conceivable explanation for the results that occurred lies in the previously mentioned factors of high educational level for the Black population in the Portland metropolitan area, and the regional makeup and residential stability of the Black population. Both factors would tend to increase PPVT scores, which would result in a higher mean ceiling item, as well as a higher mean raw score.

The results of the present study offer little support to the "non-standard language" viewpoint, which considers Black language to 
be different from standard English, rather than deficient. The patterning of errors on the PPVT could not be differentiated between Black subjects and language delayed White subjects. This, in itself, would tend to support either the "underdeveloped language system" viewpoint or the "verbal destitution" viewpoint, both of which contend that Black language is deficient in content. There are several factors, however, which might account for the results of the present study.

The previously mentioned factor of mean educational level of the community, and the possibility of a regional bias for the PPVT might account for the results in terms other than "deficit theory." A third factor which could explain why the results of the study appear to support the "deficit" viewpoint involves the use of the UCLD as the screening device for the selection of the language delayed White subjects.

The UTLD identifies language delay according to a multitude of abilities, only one of which is receptive vocabulary: the skill measured by the PPVT. It is possible that the White subjects who were involved in the study were delayed in language skills other than receptive vocabulary, such as auditory memory, visual-motor ability, or reading proficiency.

An examination of UTLD results indicates that items which involve semantic skills were answered correctly $65 \%$ of the time by language delayed White subjects. In contrast to this, test items involving language skills other than receptive or expressive semantic ability were answered correctly only $46 \%$ of the time. 
This trend suggests the White subjects were not delayed in the language skill measured by the PPVT to the extent expected. If they had been, it is possible that the PPVT results of the Black subjects and the language delayed White" subjects could have been differentiated according to the patterning of exrors, as was anticipated. 


\section{CHAPTER V}

SUMMARY AND IMPLICATIONS

\section{SUMMARY}

Diagnosis of language disorders among Black children appears to involve certain special considerations, among which is the need to differentiate between language which is deficient in content, and language which merely differs from the norm because of a non-standard cultural background. The PPVT is a widely used test in assessing language comprehension among children. However, it has not been determined whether PPVT results for a Black child are indicative of language deficiency, or merely the use of a non-standard language system.

The purpose of this study was to compare PPVT scores of Black children and language delayed White children in order to determine whether the patterning of errors can be differentiated between the two groups. The study involved twenty Black children and twenty language delayed White children between the ages of six years, six months, and seven years, six months. The subjects were from families of lower socioeconomic status. The White subjects were given the Utah Test of Language Development to establish degree of language delay.

The study was designed to determine whether either the language delayed White subjects or the Black subjects would miss any items on the PPVT significantly more often than the other group. The study sought to determine whether either group consistently made the same 
incorrect choice on items which they miss more frequently than the other group. Finally, the study was conducted to find whether the mean ceiling item reached by the two groups would be significantly different.

The results of the study indicate the patterning of errors cannot be differentiated between the two groups. No significant difference was present between the mean ceiling item reached by the groups, and only two test items were missed significantly more often by the language delayed White subjects than by the Black subjects.

It is postulated that factors which might influence PPVT results in the Black population, as well as the White population, are: 1) the mean level of education of the community; 2) the residential stability of the population; and 3) the regional area from which new residents migrate.

\section{IMPLICATIONS FOR CLINIC AND FUTURE RESEARCH}

\section{$\underline{\text { Clinic }}$}

The results of this investigation indicate that $\mathrm{Black}$ subjects in the Portland metropolitan area tend to receive PPVT scores several months lower than the norms originally established for the test. This study did not offer evidence that the bias is caused by a culturally different language system. When the results of the present study were compared with those of the Kresheck and Nicolosi study (1973), however, several factors were noted which may account for PPVT bias against subjects, including Black subjects. One of these factors is the possibility of a regional bias whereby a subject who has moved to an area 
from a different region of the country may receive PPVT results which differ from those of other subjects in the area. A second factor may be the mean educational level of the community in which the subject resides, regardless of the subject's own educational level.

When administering the PPVT, clinicians should be aware of a subject's regional background, as well as the educational level of the community where the subject lives, as these factors may influence PPVT results.

\section{Research}

This study suggests that Black subjects tend to score below the established norms on the PPVT, although the study offers no evidence that a cultural language difference is responsible for the lower scores. Additional research needs to be conducted to determine whether the factors of regional difference and community educational level do, indeed, influence PPVT results. Possible studies in this area might involve comparisons with Black and White subjects who are long term residents of the Portland metropolitan area, and Black and White subjects who have moved to this area from other regions of the country. 


\section{REFERENCES}

BARATZ, J., Language in the Economicaliy Disadvantaged Child: A Perspective. American Speech and Hearing Association, 10, 143-45 (1968).

BARATZ, J., Language and Cognitive Assessment of Negro Children: Assumptions and Research Needs. American Speech and Hearing Association, 11, 87-91 (1969).

BERETTER, C., and ENGLEMANN, S., Teaching Disadvantaged Children in the Preschool. Englewood Cliffs: Prentice-Hall (1966).

BERNARD, J., Marriage and Family Among Negroes. Englewood Cliffs: Prentice-Hall (1965).

BONNER, M., and BELEDEN, B., A Comparative Study of the Performance of Negro Seniors of Oklahoma City High Schools on the Wechsler Adult Intelligence Scale and the Peabody Picture Vocabulary Test. Journal of Negro Education, 39, 354-58 (1970).

DEUTSCH, M., The Role of Social Class in Language Development and Cognition. American Journal of 0rthopsyehiatry, 35, 78-88 (1965).

DILlARD, J., The Urban Language Study of the Center for Applied Linguistics. The Linguistic Reportex, 8, 1-2 (1966).

DILLARD, J., Black English. New York: Random House (1972).

DUNN, L., Peabody Picture Vocabulary Test. Minneapolis: American Guidance Service (1965).

FRAZIER, A., A Research Proposal to Develop the Language Skills of Children with Poor Backgrounds. In A. Jewett and others (Eds.), Improving English Skills of Culturally Different Youth in Large Cities. U.S. Government Printing Office: Washington, D.C. (1964).

GILMORE, S., Race, Residence, and SES in Responses to Articulation Test Stimuli. Southern Speech Journal, 33, 44-49 (1967).

HOPPER, $R_{c}$, and NAREPORE, $R_{\circ}$, Children's Speech: A Practical Introduction to Communicative Development. New York: Harper \& Row $(1973)$. 
JENSEN, A., How Biased Are Culture Loaded Tests? Unpublished Study, University of California: (1973a).

JENSEN, A., The Differences Are Real. Psychology Today, 7, 80-86 $(1973 b)$.

JOHN, V., The Intellectual Development of Slum Children: Some Preliminary Findings. American Journal of 0rthopsychiatry, 33, 813-22 (1963).

KRESHECK, J., and NICOLOSI, L., A Comparison of Black and White Children's Scores on the Peabody Picture Vocabulary Test. Language, Speech, and Hearing Services in the Schools, 4, 37-40 (1973).

LABOV, W., The Study of Non-standard English. Champaign, Illinois: National Council of Teachers of English (1970).

LYMAN, H., A Review of PPVT. In 0. Buros (Ed.), Mental Measurements Yearbook. New Jersey: Gryphon Press (1965).

MANDEL, R., A Longitudinal Investigation of the Stability of I.Q.'s on the PPVT with High and Low Socioeconomic Subjects. Exceptional Children, 37, 300-01 (1970).

MECHAM, M., and others, The Utah Test of Language Development. Salt Lake City: Woodruff Printing and Litho (1969).

MILGRAM, N., and 0ZER, M., Peabody Picture Vocabulary Test Scores of Preschool Children. Psychological Reports, 20, 779-84 (1967).

NIDA, E., Towards a Science of Translating. Leiden: E. J. Brill $(1964)$.

PIERCE, J., Comment Made in Linguistics Lecture (1973).

RAPH, J., Language Characteristics of Culturally Disadvantaged Children: Review and Implications. Review of Educational Research, $35,373-400$ (1965).

ROBINSON, H., and MUKEPUI, R., Language Concepts and the Disadvantaged. Educational Leadership, 23, 133-41 (1965).

STARK, J., Current Clinical Practices on Language. American Speech and Hearing Association, 13, 217-20 (1971).

U.S. Bureau of Census, Methodology and Scores of Socioeconomic Status: Working Yaper No. 15. Washington, D.C. (1960).

U.S. Bureau of Census, Census Tracts: Portland, Oregon. Washington, D.C. $(1972 a)$. 
U.S: Bureau of Census, Census Tracts: Rockford, Illinois. Washington, D.C. (1972b).

Wolfram, W., Sociolinguistic Premises and the Nature of Non-standard Dialects. In A. Smith (Ed.), Language, Communication, and Rhetoric in Black America. New York: Harper and Row (1972). 